\title{
CONDILLAC: CONOCIMIENTO Y MUNDO EXTERNO
}

\author{
Ismael MARTÍNEZ LIÉBANA
}

En este artículo pretendemos ofrecer una exposición crítica de la concepción que Condillac (1714-1780) sustenta en torno al tan debatido problema gneosológico del conocimiento del mundo externo. En concreto, nuestra intención es aquí mostrar cómo el filósofo francés, sobre la base de la celebre hipótesis de la estatua (artificio metodológico que pretende representar al hombre en el proceso de adquisición y formación de sus ideas, afectos y voliciones), confiere al sentido del tacto, en su dimensión dinámica y no meramente pasiva, el papel preponderante en el mecanismo constituyente del sentimiento de objetividad. Los llamados "sentidos subjetivos" (olfato, oído, gusto y vista) no son para Condillac vías cognoscitivas válidas de acceso a lo externo; sólo el tacto activo propiaciará para él el alumbramiento en el yo de un mundo ajeno trascendente y material. Será la sensación táctil de solidez o resistencia la que hará posible tal alumbramiento. En este sentido, el procedimiento explicativo empleado por el abate francés cuenta con elementos singulares y significativos, tales como movimiento (espontáneo en un principio, guiado por la naturaleza después) y pluralidad de sensaciones táctiles, entre las que la de solidez revélase esencial. Por tanto, tacto, movimiento, impresión de resistencia y extensión de lo corpóreo, serán los conceptos básicos esenciales que aquí habremos de desarrollar.

Ahora bien, como veremos enseguida, Condillac, en el Traité des sensations, su obra principal al respecto, no se empeña tanto en demostrar la existencia efectiva e independiente de un mundo corpóreo, como en mostrar y describir minuciosamente el mecanismo psicológico de aprehensión y constitución de ese mismo mundo, sea éste en efecto externo o pura modificación interna del 
sintiente. No obstante, la fecundidad del planteamiento Condillaciano es innegable, constituyendo su aportación en gnoseología el inicio del llamado realismo volitivo, que tiene en Destutt de Tracy, Cabanis, Maine de Birán, Wilhelm Dilthey, Max Scheler y Heidegger, a sus más conspicuos representantes.

Citamos a Condillac por la edición de sus obras filosóficas, preparada por Georges Lerroy: Oeuvres philosophiques de Condillac, texte établi et présenté par G. Lerroy, Presses Universitaires de France, en tres tomos: t. I (1947), t. II (1948), t. III (1951).

\section{Tacto y movimiento}

Ya en 1754, en la primera edición del Traité des sensations, Condillac había conferido al movimiento un papel preponderante en el proceso de aprehensión y constitución de lo externo. La motricidad del sujeto habíase convertido, en efecto, desde entonces, en el elemento esencial posibilitador de la experiencia de resistencia, alumbradora del objeto y del mundo corpóreo. El sentido del tacto, afectado de movilidad y de flexibilidad, era considerado ya entonces el responsable directo de la superación de la subjetividad y del salto a la trascendencia. No obstante, esta importancia otorgada al movimiento en el dinamismo constituyente de lo externo se acentuará progresivamente, apareciendo como pieza clave absolutamente radical en la segunda edición del Traité.

La existencia del movimiento se hace, pues, imprescindible en el proceso de descubrimiento de lo corpóreo. "Doy a la estatua el uso de todos sus miembros..." ", afirma Condillac. Esta concesión no parece arbitraria; el movimiento es consustancial con el ser sensible desde el momento mismo de su nacimiento. Como nos dice Condillac;

La mayor felicidad de los niños parece consistir en moverse: las caidas mismas no les disgustan. Una venda sobre los ojos les apenaria menos que un lazo que les privase del uso de los pies y de las manos. En efecto, es al movimiento al que deben la conciencia más viva que tienen de su existencia. La vista, el oido, el gusto, el olfato, parecen limitarla (a la estatua) en un órgano; pero el

1 CondillaC, Traité des sensations, II, 5, \$1; t. I, pág. $254 \mathrm{~b}$. 
movimiento la extiende en todas las partes, y hace gozar del cuerpo en toda su extensión.

Si el ejercicio es para ellos el placer que tiene más atractivo lo será aún más para nuestra estatua: pues no solamente no conoce nada que puede distraerle de ello; sino que incluso experimentará que el movimiento puede sólo procurarle todos los placeres de que es capaz ${ }^{2}$.

Ahora bien, si el movimiento se presenta como esencial en lo sensible, cabe preguntarse no obstante por su origen, por la causa determinante que pone en ejercicio los miembros de la estatua. No podríamos juzgar que ésta, en virtud de un designio preconcebido, los pone en movimiento; ello se hace de todo punto imposible, pues la estatua "...no sabe aún que está compuesta de partes, que pueden replegarse unas sobre otras, o extenderse sobre los objetos exteriores" ${ }^{3}$. En 1754, Condillac otorgaba al azar, a lo fortuito o casual, la potestad de producir en la estatua los movimientos de sus miembros $y$, principalmente de sus manos:

...movimientos producidos al azar - leemos alli- habiéndole procurado (a la estatua) sucesivamente sensaciones agradables y desagradables, pretende gozar de unas $y$ apartarse de las otras ${ }^{4}$.

En 1778, en cambio, es la naturaleza la que adquiere en el pensamiento de Condillac la primacía en la determinación espontánea de los movimientos de la estatua:

...Corresponde pues a la naturaleza comenzar: corresponde a ella producir los primeros movimientos en los miembros de la estatua ${ }^{5}$.

El movimiento, esencial para el descubrimiento de lo corpóreo, surge, pues, en la estatua espontáneamente. Ninguna intención preside en ésta; ningún objetivo preconcebido la induce a ponerse en acción. Fiel a una tendencia biologista en su psicología, Condillac entiende que lo conceptual, lo reflexivo,

2 Condillac, o. c., II, 5, $\$ 10 ;$ t. I, pág. 258a-b.

CONDIllaC, o. c., II, $5, \$ 1$; t. I, pág. $255 a$.

4 Condillac, o. c., édition de 1754 , II, 4, $\$ 9$; t. I, pág. $257 \mathrm{~b}$, en nota. El subrayado es nuestro.

5 Condillac, o. c., II, 5, $₫ 1 ;$ t. I, pág. 255a. El subrayado es nuestro. Cf. también, por ejemplo: o. C., II, 5, \$10; t. I, pág. 257b: "El movimiento que la naturaleza le induce a efectuar...". 
es secundario en el proceso de génesis y desarrollo de la vida del sintiente. Lo primario, lo verdaderamente radical y consustancial con el psiquismo del cognoscente es lo afectivo y pulsional y, en definitiva, en cierto modo, lo irracional. La acción, fundada en la necesidad, es anterior al concepto y en cierta medida lo determina: «...Es naturalmente, maquinalmente, por instinto y sin saberlo cómo se mueve...." ${ }^{6}$, escribe Condillac. Esta espontaneidad en los movimientos de la estatua, que la ponen en disposición de hacerle dar el salto a lo trascendente, se halla determinada así por la naturaleza, que se convierte por tanto en el verdadero principio rector del deseado descubrimiento de lo externo.

Así pues, en un principio, la espontaneidad impera en los movimientos de la estatua. Esta carece de toda intención de agitarse. Sólo después, cuando haya adquirido la conciencia de su cuerpo y de los movimientos de éste, podrá regularlos y disponer de ellos a voluntad. "He hecho observar varias veces, $y$ particularmente en mi Logique -escribe Condillac-, que no nos acontece nunca hacer una cosa con intención, sino en tanto que la hemos hecho ya, sin haber tenido el proyecto de hacerla. Es una verdad fecunda..." ${ }^{7}$. En La Logique, en efecto, Condillac subraya la prioridad de lo espontáneo o azaroso sobre lo reflexivo. Antes de toda conceptualización racional, lo originariamente natural impone su ley:

Era natural a los hombres suplir la debilidad de sus brazos por los medios que la naturaleza habia puesto a su alcance; y fueron mecánicos antes de desear serlo. Ast es como fueron logicos: han pensado antes de investigar cómo se piensa. Fue necesario incluso que pasaran siglos para hacer sospechar que el pensamiento puede estar sujeto a leyes; $y$ hoy el mayor número de ellos piensa aún sin formular semejantes sospechas ${ }^{8}$.

Los primeros hallazgos en el plano cognoscitivo, así como en el psicomotor, no se deben, pues, a una reflexión acabada, racionalmente dirigida. Corresponde a la Naturaleza, concebida como conjunto de necesidades y facultades determinadas por la constitución orgánica ${ }^{9}$, el instruirnos y aleccionarnos en los primeros instantes ${ }^{10}$ : "Resulta de esta verdad —escribe Condillac-, que

Condillac, o. c., II, 4, \$2; t. I, pág. 255b.

Condillac, o. c., II, 4, \$3; t. I, pág. 254a.

8 CONDILLAC, La logique ou les premiers developpements de l'art de penser, objet de cet ouvrage; t. II, pág. 3712 .

9 Condillac, o. c., II, 1; t. II, pág. 373a.

10 Condillac, ibidem. Cf. también: Condillac, Lait de penser, I, 9. 
la naturaleza comienza todo en nosotros: también he mostrado que, en el principio o en el comienzo, nuestros conocimientos son únicamente su obra, que no nos instruimos sino sobre la base de sus lecciones; y que todo el arte de razonar consiste en continuar como nos ha becho comenzar" "I.

Hemos de preguntarnos ahora, siguiendo con el análisis del papel que el movimiento desempeña en el proceso de captación de lo corpóreo, por el medio de que la naturaleza se vale para provocar en la estatua los movimientos y la actividad de sus miembros. A semejante pregunta, que encierra presumiblemente la clave de la investigación que emprendemos, no cabe sino responder poniendo de relieve la importancia que en Condillac presenta la dimensión afectiva o pulsional del sintiente. En efecto, la primacía de lo afectivo sobre lo racional es patente en su sistema. El placer y el dolor son en Condillac el principio y los primeros motores de toda actividad y de todo conocimiento. Esta idea, de una fecundidad insospechada en la historia del pensamiento, es constante en sus obras: «... los diferentes grados de placer y de dolor —escribe-, son la ley, segun la cual el germen de todo lo que somos se ha desarrollado, para producir todas nuestras facultades" 12 . El placer y el dolor guían el desarrollo del sintiente en todas sus transformaciones. Por ellos, el alma aprende a pensar y los conocimientos adquiridos se vinculan entre sí, formando la serie de ideas que responden a necesidades diferentes ${ }^{12}$. Como escribe Gabriel Madignier: "Condillac hace de la afectividad la fuente de la vida psicológica" ${ }^{14}$. Placer y dolor actúan en el alma y en el cuerpo, produciendo, de un lado, una serie de ideas, y de otro, una serie de movimientos ${ }^{15}$. Si en el plano cognitivo la ley de la afectividad rige la génesis y el desarrollo de las operaciones representativas del cognoscente, en el tendencial, placer y dolor se erigen igualmente en el motor determinante de la producción de los movimientos corporales:

...Es una consecuencia de su organización -escribe Condillac-, que sus músculos, contratdos por el dolor, agiten sus miembros, y que se mueva sin tener intención de ello, sin saber aún que se mueve. Puede incluso tener sensaciones agradables, cuya vivacidad no le permita quedarse en un perfecto reposo; al menos es

CONDILLAC, Traite des sensations, II, 5, 93 ; t. I, pág. $254 a$.

CONDILlaC, o. c., I, 7, \$3; t. I, pág. 239b.

CondILlaC, Traité des animaux, Conclusión; t. I, 379a.

14 G. MADINIER, Conscience et mouvement. Etude sur la philosophie franfaise de Condillac d Bergson, Ed. Nouwelaerts, París, $2^{2}$ ed., 1967, págs. 5 y sq.

${ }_{15}$ Cf. ConDILlaC, Traité des sensations, I, 2; t. I, págs. $224 a$ y sq. 
cierto que el paso alternativo del placer al dolor y del dolor al placer, debe ocasionar movimientos en su cuerpo. Si no estuviera organizada para ser movida con ocasión de sensaciones agradables o desagradables que experimenta, el reposo perfecto, al que se vería condenada, no le dejaria ningún medio para buscar lo que puede serle útil, y para evitar lo que puede dañarla ${ }^{16}$.

La actividad de la estatua prodúcese, pues, por el placer y el dolor, que se convierten así en el asiento fundamental de la psicología de Condillac ${ }^{17}$.

Es el tacto, pues, el sentido que propicia al cognoscente la revelación de lo externo. Ahora bien, condición indispensable de esa revelación es, como se ha visto, el movimiento de los miembros de la estatua ${ }^{18}$. Sin ellos, y, sobre todo, sin una cierta movilidad y flexibilidad en la mano, principal órgano del tacto ${ }^{19}$, el descubrimiento de los cuerpos (el propio y los ajenos), se haría de todo punto imposible. La constatación de lo real, concebido como conjunto de objetos materiales, es obra del tacto y, principalmente, de la mano. Lo real deviene así para el sujeto esencialmente palpabilidad, identificándose, por tanto, plenamente lo real, lo material y lo palpable. Tacto y movimiento, actuando conjuntamente, hacen, pues, posible la percepción de un mundo trascendente, independiente por entero del sintiente y de su subjetividad.

Ahora bien, ni tacto ni movimiento podrían propiciar el descubrimiento de lo externo, si lo instintivo, si lo pulsional, si una propensión natural, inexplicable empíricamente (por no reductible a la mera sensación) no forzasen la revelación. En efecto, Condillac se ve aquí obligado, renunciando así a su perspectiva estrictamente empirista, a invocar un Deus ex machina, capaz de hacer posible la percepción efectiva de lo corpóreo. Siendo la sensación el único medio con que cuenta el cognoscente para efectuar el descubrimiento, y no radicando ésta sino en el alma, se haría en verdad difícilmente explicable cómo, a partir de ella, podría operarse la superación de la inmanencia, si otro elemento, ajeno al sistema, no interviniese y no hiciese juzgar al cognoscente que sus sensaciones, en sentido estricto meras modificaciones de su conciencia,

16 Condillac, Traité des sensations, II, 5, \$2; t. I, pág. 255a-b.

17 Cf. Condlllac, o. c., II, 7, $\$$ 1; t. I, pág. 259a-b. III, 11, \$ 5; t. I, págs. 296b-297b.

18 «En tanto que ha estado inmóvil (la estatua), no ha podido tener ninguna idea de esta resistencia... Pero desde que se mueve, se toca o coge otros objetos, siente resistencia o solidez..." (Condillac, Traité des sensations, édition de 1754, I, 4, $\$ 2$; t. I, pág. 254b, en nota).

19 Cf. CondillaC, Traité des sensations, II, 12, título; t. I, pág. $273 \mathrm{a}$. 
representaban cualidades extrínsecas. Este papel corresponde a la naturaleza, que se convierte sin duda, en una de las piezas metodológicas clave del sistema condillaciano.

La naturaleza -escribe Condillac- sólo tenia pues un medio para hacerle conocer su cuerpo, y este medio era hacerle percibir sus sensaciones, no como maneras de ser de su alma, sino como modificaciones de los órganos que son otras tantas causas ocasionales ${ }^{20}$.

El mecanismo interno del descubrimiento, el «artificio" por el que el sujeto exterioriza sus estados de conciencia sensibles, permanece oculto. Cabe describir, si, detalladamente (y es lo que Condillac lleva a cabo en el Traite) el proceso por el que el sintiente aprehende un exterior, una realidad material que le trasciende; mas, en ningún caso (al menos, en el estado actual del conocimiento) es posible dar razón última del mecanismo íntimo por el que el sujeto proyecta sus sensaciones (y principalmente la de solidez) al exterior, al cuerpo propio y a los ajenos ${ }^{21}$. Es ésta, ciertamente, una confesión de ignorancia que honra en extremo a un filósofo que dedicó intensamente gran parte de su actividad intelectual a la resolución de este problema capital.

\section{Sensación y extensión}

Sobre la base del movimiento, y en apelación al principio del placer y del dolor, ha de ser, pues, posible, el descubrimiento de los cuerpos ajenos. También aquí la sensación habrá de convertirse en el necesario y legítimo punto de partida del acceso a lo objetivo. Los presupuestos metodológicos y el procedimiento explicativo serán también ahora, en lo esencial, idénticos a los ya examinados a propósito de la corporeidad íntima.

Lo corpóreo se define en Condillac, como en Descartes, por el atributo de la extensión; "...nos representamos necesariamente cada cuerpo-escribe-, como un continuo formado por la contigüidad de varios otros cuerpos extensos. Estamos forzados a representarnos así incluso aquéllos que no caen bajo los sentidos: los

20 CONDILlaC, o. c., II, 4, \$3; t. I, pág. $254 \mathrm{~b}$.

21 CONDILLAC, ibidem. Un interesante estudio sobre el particular se halla en el libro de C. Avossa, Condillac e il processo cognitivo, Ed. Spraw, Napoli, 1975. 
juzgamos cada uno compuesto de otros cuerpos extensos, estos por otros más, y ya no sabemos dónde detenernos ${ }^{22}$. La continuidad y, por tanto, la infinita divisibilidad es así la característica esencial definitoria de lo material. En oposición a la indivisible unidad del alma (substancia, por tanto, en sentido estricto), lo corpóreo es, por el contrario, un agregado infinito de partes, indefinidamente divisible ${ }^{23}$. Siendo la sensación el único medio posible de acceso a lo corpóreo, ésta, para que el tránsito a lo objetivo sea viable, habrá, pues, de reproducir el fenómeno de la extensión ${ }^{24}$. Hasta ahora, ninguna de las sensaciones examinadas ha presentado una característica tal; será preciso indagar si el tacto puede aportarla ${ }^{25}$.

En la primera edición del Traité, Condillac sostiene que la percepción de la extensión cabe incluso en cierto modo en ausencia del movimiento ${ }^{26}$. Si la uniformidad $\mathrm{e}$ indistinción del sentimiento fundamental han privado a la estatua de toda idea de extensión, al cesar aquéllas, ésta comienza a adquirir cierta realidad para ella. Como nos dice Condillac:

...no puede tener (la estatua) confusamente todas las sensaciones, distinguirlas y observarlas, si no las percibe de alguna manera unas fuera de las otras. En efecto, si el sentimiento, en tanto que ha sido uniforme, $y$ si las sensaciones, en tanto que no han podido distinguirse, la han privado de toda idea de extensión; no la privan de ello totalmente, cuando esta uniformidad y esta confusión cesan $^{27}$.

Trátase, no obstante, de una extensión vaga e indeterminada ${ }^{28}$ carente de forma y de límites. Pese a que el sentimiento fundamental no sea uniforme y se distinga en diferentes partes de su cuerpo, las varias sensaciones que la estatua experimenta así, por ejemplo, "... calor en un brazo, frio en el otro, un dolor en la cabeza, un cosquilleo en los pies, un estremecimiento en las entrañas..." ${ }^{29}$, no son para ella sino diversas maneras de ser, distintas y coexistentes, cuya

\footnotetext{
22 Condillac, Traité des sensations, II, 4, $\$ 1$; t. I, pág. $253 \mathrm{~b}$.

23 Cf. CondillaC, Essai sur l'origine des connaissances humaines, I, I, I, $\$ 6$; t. I, pág. 7a.

24 Cf. CondillaC, Traité des sensations, II, 4, \$2; t. I, págs. 253b-254a.

Cf. Condillac, o. c; t t. I, pág. 254a.

Cf. Condillac, o. c., II, 3, título, édition de 1754; t. I, pág. 252, nota b.

Condillac, o. c., II, $3 \$ 2$, édition de 1754; t. I, pág. 253, nota a.

Cf. CONDILLAC, ibidem.

Cf. CondillaC, o. c., II, 3, \$1; t. I, pág. 253a.
} 
yuxtaposición no le confiere en modo alguno la idea compleja de extensión ${ }^{30}$. Es lo que, incluso en la primera edición del Traite, Condillac sostiene:

...Esta idea no es, pues, para ella -escribe-, más que la percepción de varias maneras de ser, que coexisten, y que se distinguen; percepcion en la que no sabria encontrar la nocion de ningún cuerpo; porque, no habiendo tocado todavia nada, no sabe que sus maneras de ser dependen de una materia sólida ${ }^{31}$.

Ya a propósito del sentido de la vista, Condillac habla abordado el tema de la percepción de la extensión. En efecto, había mantenido que tal sentido aporta al cognoscente una cierta idea de extensión. No obstante, sobre este punto, Condillac ha experimentado una evolución constante. En el Essai sur l'origine des connaissances humaines sostiene que la vista, por sí sola, aporta al sujeto, de forma inmediata, la espacialidad y la extensión, con las figuras y los tamaños, las situaciones y las distancias ${ }^{32}$. En cambio, en la primera edición del Traité, como ya sabemos, Condillac no concibe que una sensación de color, objeto propio e inmediato de la vista, aporte al cognoscente idea alguna de extensión:

...Que esté modificado (el yo de la estatua) por una superficie azul ribeteada de blanco, ¿acaso no se percibirá a sí mismo como un azul ilimitado? Uno tenderia en principio a creerlo; sin embargo el sentimiento contrario es mucho más verosimil.

La estatua no puede sentirse extensa en cuanto a esta superficie, sino en cuanto que cada parte le dé la misma modificación: cada una debe producir la sensación del azul. Pero si es modificada del mismo modo por un pie de esta superficie, por una pulgada, por una linea, etc., no puede representarse en esta modificación un tamaño más bien que otro. Por tanto, no se representa ninguno. Una sensación de color, pues, no conlleva una idea de extension ${ }^{33}$.

30 "Estas naneras de ser -escribe Condillac-, que observa a la vez, coexisten, se distinguen más o menos, y están a este respecto unas fuera de las otras: pero puesto que de ello no resulta ni contigüidad, ni continuidad, no podrian dar a la estatua ninguna idea de extensión." (CONDILLAC, Traité des sensations, II, 3, $\$$ 1; t. I, pág. 253a.

31 Condillac, o. c., II, $3, \S 2$, édition de 1754; t. I, pág. 253, nota a.

32 Cf. CONDILLAC, Essai sur l'origine des connaissances humaines, I, VI.

33 CondillaC, Traité des sensations, I, 11, \$8; t. I, pág. 247, nota a. 
Si esto es así por lo que respecta a un color simple, cuando se trata de varios, Condillac admite en la estatua una cierta percepción de extensión. Prodúcese aquí, por tanto, un fenómeno similar al que tenía lugar a propósito de la diferenciación y diversificación del sentimiento fundamental. En la captación una pluralidad de colores, la estatua, aunque vaga y confusamente, se siente de alguna manera extensa. Esta afirmación hállase ciertamente en abierta contradicción con lo que precede. En efecto, si cada impresión coloreada, aisladamente considerada, es inextensa, si la estatua no se siente delimitada por un color determinado, ¿no debe ocurrir lo mismo cuando se trata de varios colores? Una suma de ceros da siempre como resultado cero. De esta incoherencia Condillac se ha percatado pronto, reconociendo en la segunda edición del Traité que no cabe hacer extensión sino con extensión ${ }^{34}$.

La vista, por tanto, confiere al cognoscente una extensión meramente vaga, confusa, una especie de materia de extensión ${ }^{35}$. Por ello mismo, no aporta a la estatua tampoco las nociones de situación ni de movimiento; pues, la de situación, supone que se vea un objeto en un lugar determinado, y la de movimiento, que se capte visualmente el cambio de situación de ese objeto. Tampoco confiere esta extensión a la estatua idea alguna de tamaño ni de figura, pues ésta no es sino un tamaño determinado y circunscrito, y el yo, que se identifica con la totalidad de colores que lo impresionan, se extiende indefinidamente sin ser circunscrito por nada ${ }^{36}$.

Así pues, la vista, por sí sola, al igual que el tacto, carente de movimiento, no proporciona a la estatua más que una noción imprecisa e indefinida de extensión. A este respecto Gabriel Madignier, en la obra ya citada, escribe: "...Hay que distinguir dos cosas: la intuición de extensión y la percepción de un objeto figurado. La vista proporciona la primera, pero solo el tacto sugerirá la segunda..." ${ }^{37}$. El problema será, pues, pasar de la percepción de una extensión vaga y confusa a otra precisa y determinada.

Pese a que en la doctrina definitiva de Condillac esta percepción se atribuya propiamente al tacto, su concepción al respecto no fue empero siempre la

34 Cf. Condillac, o. c., II, 4, \$1; t. I, pág. $253 \mathrm{~b}$.

35 Cf. Raymond LenoIR, Condillac, Ed. Alcan, París, 1924, pág. 76. Agel J. CappelletTr, Introducción a Condillac, Ed. Universidad de Zulia, Maracaibo, 1973, págs. 109-110.

36 Cf. Condillac, o. c., I, 11, \$8; t. I, pág. 248a.

37 G. MADINIER, Conscience et mouvement. Etude sur la philosophie française de Condillac à Bergson, pág. 15. 
misma. En efecto, en el Essai, mantiene una posición nativista, que considera a la extensión como noción primitiva y constante, aprehensible directa e inmediatamente por todos los sentidos. Así, la exterioridad, el sentimiento de espacialidad y profundidad, notas características de la extensión, son consideradas allí el objeto propio y directo de la sensación en cuanto tal, con independencia del tipo específico del que se trate:

Hay, pues, tres cosas que distinguir en nuestras sensaciones: $10^{\circ}$ la percepción que experimentamos. $2 .^{\circ}$ La relación que hacemos de ella a algo fuera de nosotros. $3 .^{\circ}$ el juicio de que lo que referimos a las cosas, pertenéceles en efecto.

No hay ni error, ni oscuridad, ni confusión en lo que ocurre en nosotros, ni tampoco en la relación que hacemos de ello al exterior ${ }^{38}$.

La sensación reveladora de lo corpóreo habrá, pues, de reproducir cabalmente el fenómeno de la extensión ${ }^{39}$. Ahora bien, a juicio de Condillac, sólo por la sensación de solidez o resistencia cabrá hacerse cargo de esa extensión. No obstante, también en esto Condillac experimenta una sensible evolución. En efecto, en la primera edición del Traité, el juicio de exterioridad aparecía vinculado a sensaciones de doble contacto, esto es, a impresiones en sí mismas inextensas ${ }^{40}$. Ello es sin duda debido a que Condillac, en esa fecha, y pese a ser el objetivo fundamental del Traité, no habia profundizado sin embargo suficientemente en ese tema. Pensaba, como hemos visto más arriba que la yuxtaposición de impresiones simultáneas, en sí mismas inextensas (fuesen táctiles o visuales), podían empero reproducir en cierto modo el fenómeno de la extensión. Reflexionando más tarde sobre el problema, llevado a ello por las objeciones levantadas contra él por sus adversarios, recapacita y confiesa abiertamente no haber acertado desde un principio en la solución del problema planteado ${ }^{41}$. Por eso, en la segunda del Traité, Condillac vuelve sobre el tema, precisando y perfeccionando sus conceptos. Añade en la segunda parte un capítulo enteramente nuevo, el cuarto, donde establece a modo de necesaria introducción a la exposición definitiva, ciertos principios de extraordinaria significación. Por un lado, que "no podríamos hacer extensión sino con

38 CondILlaC, Essai sur l'origine des connaissances humaines, I, I, II, $\$ 11$; $t$, , pág. 9a.

39 Cf. Condillac, Traité des sensations, II, 4, $\$ 2$; t. I, págs. 253b-254a.

40 Cf. CondillaC, o. c., II, 5, $\$ 2$, édition de 1754; t. I, pág. 255, nota a.

4I Cf. CondillaC, Extrait raisonné du Traité des sensations, II; t. I, pág. 329b-330a. 
extensión..." ${ }^{42} ;$ y, por otro, que la sensación que la reproduzca y, por tanto, que revele lo corpóreo, habrá de estar igualmente investida de la propiedad de la extensividad ${ }^{43}$. En virtud de tales principios, Condillac entiende que la sensación apta para revelar la exterioridad y la noción de objeto ha de hallarse en la impresión de obstáculo, que opone entre sí a dos sólidos que mutuamente se excluyen. En la captación de la impenetrabilidad, o más bien, en la aprehensión de la sensación de resistencia que la revela, hállase la fuente originante del mundo externo, la raíz generadora del objeto. Sin esa sensación de obstáculo, sin esa impresión de resistencia que lo corpóreo opone al movimiento espontáneo del cognoscente, este no descubriría un fuera de sí, un mundo ajeno y por completo diferente de su yo sensitivo ${ }^{44}$. Como escribe Georges Le Roy: “... es en impresiones en si mismas extensas como son dadas las ideas de espacio y de realidad exterior" ${ }^{45}$.

Ahora bien, ¿qué mecanismo concreto lleva a la estatua al descubrimiento de los cuerpos ajenos?, ¿ cómo, sobre la base de la sensación de solidez o resistencia, surge para ella el conocimiento de entidades materiales, distintas y extranas a su cuerpo propio? Teniendo en cuenta lo hasta aquí examinado, la respuesta a estas preguntas parece sencilla: si la estatua sólo coloca las manos sobre su propio cuerpo, no podrá por menos de creerse sola en el mundo. "...Pero si toca un cuerpo extraño, el yo, que se siente modificado en la mano, no se siente modificado en ese cuerpo. Si la mano dice yo, no recibe la misma contestación. La estatua juzga por eso estas maneras de ser por completo extrañas a ella. Como ha formado su cuerpo, forma todos los demás objetos. La sensacion de solidez que les ha dado consistencia en un caso, se la da también en el otro; con esta diferencia, que el yo, que se respondia, deja de responderse» ${ }^{46}$. Como se ve, la explicación de Condillac no es precisamente oscura ni enrevesada. La simplicidad de sus análisis es posiblemente la nota más significativa y característica de su especulación filosófica. Mediante el tacto, la estatua descubre otros cuerpos porque su yo, capacidad sensitiva, no se reconoce en los objetos tocados; el eco que dejaba sentirse al tocarse a sí misma, ha desaparecido aquí por completo. El yo, identificado enteramente con la pura subjetividad sensorial, que

\footnotetext{
42 Condillac, Traité des sensations, II, 4, $\$ 1$;. I, pág. 253b.

43 Cf. Condillac, o. c., II, 4, $\$ 2$; t. I, págs. 253b-254a.

44 Cf. Condlllac, o. c., II, 5, $\$$; t. I, pág. 256a-b.

45 G. LE RoY, La psychologie de Condillac, pág. 144.

46 Condillac, Traité des sensations, II, 5, 5 ; t. I, pág. 257a.
} 
se respondía a sí mismo al deslizarse la mano sobre una parte de su cuerpo, cesa ahora de responderse; y en ese silencio, en esa ausencia, en esa soledad radical, la estatua, paradójicamente, descubre un mundo por completo ajeno a su yo y a su cuerpo. Como nos dice el propio Condillac:

...Cuando varias sensaciones distintas y coexistentes son circunscritas por el tacto en limites en que el yo se responde a si mismo, toma conocimiento de su cuerpo; cuando varias sensaciones distintas y coexistentes son circunscritas por el tacto en limites en que el yo no se responde, tiene la idea de un cuerpo diferente del suyo ${ }^{47}$.

Al descubrir cuerpos en los que no se reconoce, la estatua se asombra de no hallarse en todo lo que toca. "...Extiende los brazos como para buscarse fuera de si; y no puede aún juzgar si no se encontrará alli: solo la experiencia podrá instruirle acerca de ello» ${ }^{48}$. Previsiblemente, la estatua coloque sus manos sobre la cabeza, el pecho, las piernas, los pies: haciendo esto, se encontrará en todo lo que toque; el yo se sentirá modificado tanto en la mano que toca, como en las partes de su cuerpo que son tocadas. Coloca ahora la mano sobre una mesa, sobre una silla, sobre el suelo ..., en todos estos objetos no se encuentra a sí misma. No obstante, ella sigue extendiendo los brazos, como si pretendiese encontrarse en los nuevos objetos que va tocando; no sabe si se hallará o no; sólo la experiencia, una vez más, puede aleccionarla a este respecto. Así, del asombro de no ser todo lo que toca, nace la inquietud de saber dónde está, "... y, si puedo expresarme asi, hasta dónde está...” ${ }^{49}$. He ahí, pues, el proceso por el que, según Condillac, el cognoscente debe descubrir la existencia de cuerpos circundantes.

Consecuencia inmediata de este trascendental y prodigioso descubrimiento, es que los deseos de la estatua, sus necesidades y, en definitiva, su dimensión volitiva toda, no tienen ya por objeto sus propias modificaciones o maneras de ser, sino los objetos del entorno, los cuerpos, cuya existencia acaba de revelársele. Su amor ya no es el amor de sí misma, sino que se dirige hacia los objetos palpables. Sus deseos, por tanto, la arrastran continuamente fuera de $s^{50}$.

47 Condillac, o. c., II, 5, \$6; t. I, pág. 257 a.

48 Condillac, o. c., II, 5, \$7; t. I, pág. $257 \mathrm{~b}$.

49 Condillac, o. c., II, 5, \$8; t. I, pág. 257b.

so Cf. Condillac, o. c., II, 6, \$ 7; t. I, pág. 259a. 
Así pues, en apelación a la sensación táctil de resistencia, que es en definitiva una sensación muscular, Condillac entiende haber justificado debidamente el paso de lo interior a lo exterior, el tránsito del yo al mundo. Ningún otro sentido, aparte del tacto, puede captar la impresión de obstáculo que opone entre sí a un cognoscente (o más bien, a un volente) y a un objeto por entero diferente de él. En esa oposición, captable únicamente por vía táctil, revélase a la conciencia la existencia de una realidad, de un orden de entidades, que, por opuestas al yo cognoscente, nada tienen que ver con él. La realidad corpórea, por cuanto es aprehendida primariamente a través de impresiones táctiles, es definida esencialmente como palpabilidad; y puesto que la nota característica de esa palpabilidad es la captación de una oposición entre un tocante y un tocado, tal realidad deviene así para el yo pura resistencia y solidez. Si la estatua, dotada de todos sus sentidos, permaneciese siempre inmóvil, o si, en movimiento, no llegase nunca a experimentar sentimiento alguno de obstáculo o resistencia, creeríase sola en el mundo. Sus impresiones visuales, auditivas, olorosas y gustativas, por no aprehender sensación alguna de resistencia, no le transmitirian idea alguna de objeto, ni siquiera, de espacialidad o exterioridad. Limitaríanse sólo a revelarle su propia existencia, definida diferentemente, según los diferentes sentidos. Únicamente el choque, posible por vía táctil, que transmite al sujeto la impresión de resistencia, puede propiamente alumbrar la realidad de un mundo ajeno. El mérito de Condillac, a parte de haber aportado al problema del conocimiento del mundo externo una solución completa y acabada, ha consistido primariamente en haber abierto, para la resolución de este problema radical, una vía nueva, fecunda y llena de posibilidades; vía que seguirá, entre otros, Maine de Biran, quien la recorrerá hasta sus últimos y más difíciles tramos ${ }^{51}$.

\section{Valor y alcance del conocimiento sensible}

La existencia de lo corpóreo hállase, pues, establecida. La sensación táctil de resistencia ha roto las estrechas ligaduras que mantenían a la estatua sumida en

51 Cf., por ejemplo, los interesantes estudios de F. RHETORE, Condillac ou l'empirisme et le rationalisme, Ed. Slatkine Reprints, Genève, 1971, reimpresión de la edición de París, 1864; y N. ISAR, "Condillac et l'Idéologie française dans les préoccupations de Nicolae Rosetti-Roznovanu", in Rev. Filoz., (1972), XIX, n. ${ }^{\circ}$, págs. 671-679. 
la inmanencia de su conciencia. El yo, privado hasta ahora de toda relación extrasubjetiva, ha dado el salto a lo objetivo, abriéndose a un orden de realidad insospechado hasta ahora para él. El choque, el encuentro, el enfrentamiento, que el movimiento ha hecho posible y que el tacto ha propiciado, han logrado transmitir a la conciencia la sensación de solidez, haciendo así que la estatua descubra su cuerpo y los cuerpos del entorno.

Ahora bien, hemos de preguntarnos aquí por el grado de conocimiento que la estatua, a través del tacto, obtiene de lo corpóreo. ¿A qué se reduce, en efecto, la idea que ella posee, tanto de su cuerpo, como de los objetos que la circundan?, ¿logra el tacto penetrar en la esencialidad misma de lo material o, por el contrario, limítase tan sólo a presentar de ello un aspecto determinado y relativo? Condillac es en esto claro y contundente. La estatua, lejos de acceder con sus sentidos a la mismidad e intimidad de los cuerpos que el tacto le ha hecho descubrir, sólo capta en ellos las cualidades sensibles, inherentes sensu stricto únicamente en su propia conciencia. Las sensaciones aprehendidas por el resto de sentidos serán proyectadas por el del tacto al exterior, haciendo que inhieran entonces en los objetos mismos. Pues bien, el tupido velo de impresiones sensibles que envuelve a los cuerpos, velo con que el yo de la estatua se identificaba antes de la aparición del tacto y que ahora cubre la realidad material recién descubierta, impide la penetración esencial, al tiempo que hace posible la cognoscibilidad de los entes corpóreos, definidos en su relación con el sintiente. Así, como dice Condillac: "...La idea de tal naranja es el color, la forma, el sabor, el olor, la solidez, el peso, etc." 52 , cualidades sensibles, cuya realidad, por tanto, es función también del sujeto percipiente. De lo corpóreo, pues, carécese de un conocimiento que trascienda el mero ámbito de lo sensible; ámbito que, por otra parte, parece incapaz de penetrar en la esencialidad misma de la materia. Cada objeto defínese como conjunto o colección de cualidades sensibles; y lo material, en general, como conjunto o reunión de cualidades propiamente táctiles:

...Ella (la estatua) ve, por ejemplo, la solidez, la extensión, la divisibilidad, la figura, la movilidad, etc., reunidas en todo lo que toca; $y$ tiene, por consiguiente, la idea de cuerpo. Pero si se le preguntase lo que es un cuerpo y pudiese responder, enseñaria uno, y diría, es esto, es decir, esto en que encontrareis al mismo tiempo solidez, extensión, divisibilidad, figura, etc. ${ }^{53}$.

52 Condillac, Traité des sensations, IV, 6, $\$ 2$; t. I, pág. $306 \mathrm{~b}$.

53 Condillac, o. c., IV, 6, \$9; t. I, pág. 308a. 
La naturaleza de lo corpóreo redúcese, pues, a lo sensible. Ni siquiera el filósofo que se jacta de una penetración de espíritu superior, puede ir con su saber más allá. Para él, como para la estatua, la realidad material sólo puede definirse por apelación a las cualidades sensibles que el tacto descubre en la sensación de resistencia y que hace proyectar al exterior. Sólo un lenguaje confuso e impreciso produce la apariencia de un conocimiento más exhaustivo ${ }^{54}$.

El alcance del conocimiento sensible en la aprehensión de lo material es, pues, limitado. Por el tacto, se ha logrado la revelación existencial, mas la penetración esencial permanece impracticable. Ello se debe, sin duda, a que los sentidos (incluso el tacto), lejos de poseer una finalidad cognoscitiva teorética, tienden, por el contrario, a un objetivo práctico. En este sentido, para el sintiente, poco importa que sus sensaciones reproduzcan fidedignamente las cualidades mismas de los objetos; el carácter afectivo de que hállanse revestidos (el placer y el displacer que en él provocan) basta para guiar y regular su actividad en pro de su conservación, fin último del existir del sintiente ${ }^{55}$. "Así pues, ella (la estatua) no percibe los cuerpos en sí mismos, sólo percibe sus propias sensaciones" ${ }^{56}$. Esta es la conclusión de Condillac. Según ella, la incertidumbre acerca del en sí de lo material es absoluta. La estatua, como es sabido, aprende, por las enseñanzas del tacto, a referir todas sus sensaciones al exterior, considerando así que son las cualidades mismas de los objetos. Mas, este juicio de proyección, ¿es certero?, "... ¿Hay, pues, en los objetos sonidos, sabores, olores, colores? ¿Quién puede asegurarlo? No es ciertamente ni el oido, ni el olfato, ni el gusto, ni la vista: los sentidos por si mismos no pueden enseñarle sino las modificaciones que experimenta..." "57. El sentido, en cuanto tal, sólo capta sensaciones, y éstas, no siendo más que meras modificaciones de la conciencia, no pueden llevar en sí la impronta de la esencialidad de lo corpóreo. Ni siquiera la extensión puede atribuirse de modo absoluto a lo material; ella no es tampoco sino una cualidad sensible más y, como tal, existente en principio tan sólo en relación con el sintiente. "...Por consiguiente - nos dice Condillac-, el tacto no es más digno de crédito que los demás sentidos: $y$ puesto que se reconoce que los sonidos, los sabores, los olores y los colores no existen en los objetos, podría ser que la extensión tampoco existiesen ${ }^{58}$.

\footnotetext{
Cf. Condillac, o. c., IV, 6, $\$ 10$; t. I, pág. 308a.

Cf. Condillac, o. c., IV, 8, $\$ 5$; t. I, pág. 313a.

Condillac, o. c., II, 5, \$6; t. I, pág. 257a.

Condillac, o. c., IV, 5, 9 1; t. I, pág. 306a.

8 Condillac, o. c., IV, $5, \S 1$; t. I, pág. 306a.
} 
Mas, ¿no es acaso la extensión la esencia misma de lo corpóreo?, ¿no se define la materia, como Descartes había hecho, como pura extensión, por oposición al pensamiento, naturaleza propia e íntima de lo anímico? Condillac, es cierto, no se siente cómodo ante estas preguntas; poner en duda la existencia real y efectiva de la extensión con independencia de toda captación sensible, parece poner en duda la existencia misma de los cuerpos. Mas, Condillac no niega ésta; ¡cómo habría de negarla, si el tacto acaba de revelarla? Los cuerpos están ahí, se nos imponen, querámoslo o no, cada vez que nuestros sentidos (y principalmente el tacto) se ponen en ejercicio, sin embargo, ¿qué sabemos realmente acerca de ellos, si no es a través de las sensaciones?, ¿y acaso no percibimos también la extensión por el intermedio de las sensaciones?, o más bien, ¿̨no es la extensión una sensación más, como lo es el olor, el color, el sonido y el gusto?

Si no hay extensión, se dirá tal vez, no hay cuerpos. Yo no digo que no haya extensión, digo sólo que no la percibimos sino en nuestras propias sensaciones. De donde se deduce que no vemos los cuerpos en si mismos. Quizá sean extensos, e incluso gustativos, sonoros, coloreados, odoriferos: quiza no sean nada de eso. No sostengo ni lo uno ni lo otro; $y$ espero a que se pruebe que son lo que nos parecen, o que son algo por completo diferente.

Aunque no hubiera extension, ésta no seria una razón para negar la existencia de los cuerpos. Todo lo que podria y deberia razonablemente inferirse, es que los cuerpos son seres que ocasionan en nosotros sensaciones, y que tienen propiedades sobre las cuales no podriamos asegurar nada ${ }^{59}$.

El escepticismo de Condillac por lo que a la esencia de lo corpóreo respecta es, pues, manifiesto. El tacto ha revelado su existencia; mas lo que ni el tacto ni los demás sentidos pueden revelar es su esencia, el conjunto de propiedades que, con independencia de toda aprehensión sensible, hunden sus raices en los cuerpos mismos.

\section{Observaciones finales}

El problema que prioritariamente preocupaba a Condillac en el Traité ha quedado finalmente resuelto. Sobre la base de sus principios, esto es, en apelación

59 Condillac, o. c., IV, $5, \$ 1$, en nota; t. I, pág. 306a. 
estricta a la sensación como fuente originaria del conocimiento y al contenido afectivo de ésta, se ha logrado dar cuenta del ineludible sentimiento de exterioridad, así como de la constitución perceptual del cuerpo propio y de los ajenos. Para ello, el sentido del tacto se ha revelado pieza clave. Solo el, en efecto, puede aportar al cognoscente la sensación de solidez o resistencia, necesaria para operar el problemático descubrimiento.

Ahora bien, ¿qué sentido exacto presenta la demostración condillaciana del mundo externo? o, formulada la cuestión en otros términos: ¿qué demuestra realmente Condillac con su prueba? Nuestra tesis, que se halla en cierto modo en contradicción con la intención última de Condillac en el Traité y que, sin embargo, aparece avalada por numerosos textos de éste, apunta a una interpretación estrictamente idealista del pensamiento del abate francés. Según ella, en el Traité, no se accede, ni siquiera por vía táctil, al mundo objetivo de los cuerpos, en cuanto que independiente de toda percepción sensible. Desde luego, Condillac, como hemos visto, no cree en ningún momento que quepa el acceso cognoscitivo a la mismidad esencial de lo corpóreo; mas, ni siquiera, a nuestro juicio, cabe, según sus principios, la captación del existir en sí de los cuerpos, esto es, la aprehensión directa y sin mediación sensible de la existencia real de la materia ni, en general, de nada ajeno a la subjetividad misma del sintiente. A nuestro juicio, y es lo que en este artículo defendemos, Condillac ha logrado con el Traite, no tanto superar el idealismo berkeleyano, traspasando los límites de la inmanencia, como explicar empírica y minuciosamente el mecanismo psicológico por el que aparece en el cognoscente el irresistible sentimiento de exterioridad. Condillac, inducido por las observaciones de Diderot, pretende establecer críticamente, aún manteniendo vigentes los principios idealistas de Berkeley ${ }^{60}$, la creencia espontánea del sentido común en la existencia trascendente de la materia. Es así como supone en un principio a la estatua afectada por sensaciones privadas de toda referencia extrasubjetiva. Este punto de partida hacíase absolutamente imprescindible, pues reflejaba bien a las claras la clausura de la conciencia, que toda posición idealista sustenta. Sobre esa base, era necesario justificar la realidad de lo externo, dar cuenta de una existencia ajena y por entero independiente de la sensación misma, con la

60 Como sabemos, CONDILLAC había escrito en el Essai:

"Sea que nos elevemos - para hablar metaforicamente-, hasta los Cielos; sea que descendamos a los abismos, no salimos de nosotros mismos jamás, y nuestro pensamiento es lo que conocemos solamente." (Essai sur l'origine des connaissances humaines, I, I, I, $\$ 1 ; \mathrm{t}$. I, pág. Ga). 
que la estatua se identificaba plenamente. Tal justificación sólo es posible desde la sensación misma, desde un tipo de sensación (la sensación táctil de resistencia) que presenta la peculiaridad de transmitir al cognoscente el sentimiento de oposición, de obstáculo, indispensable para alumbrar en su conciencia la noción de objeto y de mundo externo.

Ahora bien, lo que con este procedimiento explica realmente Condillac, no es la aprehensión de un exterior material en sí mismo considerado; Condillac no logra propiamente con la sensación de solidez que la estatua dé el salto al exterior y se encuentre con los objetos mismos al margen de sus sensaciones. Con él explica más bien (y ésta, insistimos, es nuestra tesis) meramente la aparición en el sintiente de un sentimiento (el de exterioridad), ausente en su conciencia hasta el surgimiento de la impresión de resistencia. La meta alcanzada es, pues, sensiblemente más modesta que la inicialmente trazada. El yo ha descubierto, sí, los cuerpos y el mundo exterior; mas, puesto que el único vehículo para ello ha sido la sensación, su captación es, por así decir, inmanente: no percibe lo corpóreo ni lo exterior sino en sí mismo; lejos, pues, de irrumpir la conciencia en el mundo, es éste, por el contrario, el que se introduce en aquélla, haciendo así que el sujeto, sin salir de sí mismo, aprehenda lo objetivo y lo corpóreo. Es lo que expresa Condillac en los siguientes términos:

Solo me siento a mi mismo, y es en lo que siento en $m i$ cómo veo el exterior: o más bien no veo el exterior; pero me he acostumbrado a ciertos juicios, que transportan mis sensaciones donde no se hallan ${ }^{61}$.

De este modo, las cualidades sensibles de los objetos (tangibles o no) siguen siendo meras modificaciones del sintiente, simples maneras de ser de su conciencia, referidas ahora, tras la aparición de la sensación táctil de resistencia, al exterior, que, según lo dicho, no tiene tampoco entidad sino en la subjetividad misma, único ámbito de lo inmediato, directo e indubitable. "Desde ese momento ${ }^{62}$-escribe Condillac-, me parece que mis maneras de ser dejan de pertenecerme: hago con ellas colecciones exteriores: con ellas formo todos los objetos cuyo conocimiento adquiero..." "63. Así pues, el idealismo de Berkeley, como querian Diderot y Condillac mismo, se supera, si, más a costa de asumir dogmáticamente y sin

\footnotetext{
61 Condillac, Traité des sensations, IV, 8, $\$ 1$; t. I, pág. $310 \mathrm{~b}$.

62 Desde la aparición de tacto y movimiento.

63 CondillaC, Traité des sensations, IV, 8, $\$ 2$; $\mathrm{t}$ I, pág. 31 la.
} 
prueba demostrativa auténtica, la existencia independiente de un mundo material. Condillac no niega, ciertamente, la realidad absoluta de lo corpóreo; no obstante, confiesa abiertamente su ignorancia sobre ello, al considerar todas las propiedades sensibles de los cuerpos (incluida la extensión) como simples maneras de ser del sintiente; la realidad de lo material permanecerá así un enigma, siendo esa $X$ la que provoque en la conciencia las diversas sensaciones del sujeto ${ }^{64}$.

Por otra parte, hemos de preguntarnos también aquí si Condillac, en su demostración de la existencia del mundo material, permanece fiel al principio sensista, inicialmente trazado, de derivar el descubrimiento de tal mundo del estricto dato sensorial o si, por el contrario, renunciando a él por imperativos insoslayables, se ve forzado para ello a invocar instancias extra-sistemáticas de carácter supra-empírico. Ya apuntamos en páginas anteriores que, a nuestro juicio, la revelación de lo externo hacíase impracticable, sensu stricto, por apelación exclusiva a la sensación (entendida como simple modo de ser del pensamiento) y a su dinamismo estrictamente interno. Indicamos que el descubrimiento de lo corpóreo sólo podía efectuarse si, a parte de la sensación (necesario punto de partida), se invocaba una fuerza instintiva y misteriosa, que Condillac denominaba naturaleza, y a la que se atribuía en rigor la proeza del descubrimiento. En esto, no nos sentimos solidarios con el juicio de G. Le Roy, para quien la revelación, tanto en la primera como en la segunda edición del Traité, débese exclusivamente a la sensación de solidez, entendida ella también como simple manera de ser de la conciencia ${ }^{65}$. De ahi que suscribamos por entero las afirmaciones de G. Lyon, para quien Condillac, apelando a la naturaleza en la revelación de lo material, emparenta directamente con la solución de Malebranche:

A decir verdad -escribe-, la solución desarrollada en la edición princeps y la que se ha recogido en ediciones ulteriores no difieren en nada esencial: aquélla simplificaba en demasia el prodigio y lo hacia operar, sin mas ambajes, a la estatua vivificada; éstas testimonian la grandeza del milagro $y$, a falta de poder atribuirlo a la iniciativa del niño hacen que sea la naturaleza la que lo lleve a cabo. Pero la naturaleza se comporta aqui del mismo modo que el Dios de Malebranche, ya que, por una entente inesperada, el maestro sensualista coinci-

64 Cf. CONDILlaC, o. c., IV, 5, \$ 1; t. I, págs. 305b-306a.

65 Cf. G. Le Roy, La psichologie de Condillac, pág. 145. 
de con el célebre cartesiano en reconocer en el cuerpo y su acción una simple "causa ocasional" 66 .

No cabe duda de que la solución aportada por Condillac al problema del conocimiento del mundo externo es atractiva y original, al tiempo que extraordinariamente fecunda. En efecto, en el transcurso del siglo XIX, numerosos pensadores se vuelven hacia Condillac, tratando de extraer de su teorfa los elementos más complejos y valiosos, que posibiliten desarrollos y profundizaciones de mayor envergadura. Como escribe Ángel J. Cappelletti en su estudio sobre Condillac:

...La teoria del descubrimiento del mundo exterior mediante la sensación de solidez y de resistencia, que es, por cierto, una teoria fundamental en Condillac, fue reeditada a comienzos del siglo XX, en un contexto no precisamente empirista sino vitalista e irracionalista, por Dilthey ${ }^{67}$. Para este, en efecto, la convicción de que existe un mundo externo se explica por una conexión vital que se produce en el sentimiento, en el impulso y en la voluntad y no por una conexión mental, como en el caso de Condillac.

El hombre es, para Dilthey, antes que nada un sistema de impulsos $y$, por eso, no puede dejar de experimentar un sentimiento de resistencia cuando dichos impulsos chocan con las cosas del mundo. De este sentimiento de resistencia - que para Condillac surge en él por la sensación tactil- nace la distinción, primero oscura y limitada, entre el sujeto y el objeto, entre el yo y el noyo.

No se refiere entonces a una sensacion sino a un movimiento de la voluntad $o$, si se quiere, a una intuicion volitiva. Pero entre Condillac y Dilthey, hay a traves del siglo XIX, toda una cadena de pensadores que vincula directamente al uno con el otro... ${ }^{68}$.

El primero de tales pensadores es Destutt de Tracy (1754-1836). Discípulo y continuador de la filosoffa de Condillac, insiste sobre este punto capital de su doctrina. Según él, es en la resitencia que la materia opone a los movi-

66 Georges LYON, Introduction au Traité des sensations de Condillac, Ed. Felix Alcan, París, nouvelle édition, 1886, págs. 16-17.

67 Cf. W. DilTHEY, Psicologia y teoria del conocimiento, Ed. Fondo de Cultura Económica, México, 1945, págs. 153-201.

68 Angel J. CAPPELleTTI, Introducción a Condillac, págs. 122-123. 
mientos del sintiente donde ha de buscarse la prueba definitiva de la realidad del mundo exterior. Según él, si no hubiésemos percibido la impresión de resistencia, "...no habríamos descubierto nunca la existencia de cuerpos ni la de nuestros brganos" ${ }^{69}$. Ahora bien, puesto que la sensación de resistencia no es posible sin la previa condición del movimiento, puede decirse en definitiva que es por éste por el que descubrimos la existencia de realidades exteriores:

...es moviéndonos -escribe- como descubrimos si existe algo o nada a nuestro alrededor, en torno a nuestra facultad de sentir y de querer ${ }^{70}$.

Sin duda, Destutt de Tracy acentúa con respecto a Condillac la importancia del movimiento en la génesis del conocimiento del mundo externo; sin él, la sensación de solidez o resistencia revelaríase imposible y, por tanto, la clausura de la conciencia permanecería constante. De ahí que, al resumir su pensamiento, Destutt de Tracy se exprese en los siguientes términos:

Queda, pues, convenido que, mientras que no hagamos sino sentir, recordar, juzgar y querer, sin que ninguna acción se siga de ello, no tenemos conocimiento más que de nuestra existencia, y no nos conocemos a nosotros mismos sino como un ser sintiente, como una simple potencia sintiente, sin extension, sin forma, sin partes, sin ninguna de las cualidades que constituyen los cuerpos.

Queda también convenido que desde que nuestra voluntad pasa al acto, desde que nos hace mover, la fuerza inercial de la materia de nuestros miembros nos lo advierte, nos da la sensación de movimiento, lo que quizá no nos enseñe nada nuevo; pero cuando este movimiento, que sentimos, que quisieramos continuar, es detenido, descubrimos ciertamente que existe otra cosa a parte de nuestra capacidad sintiente. Este algo es nuestro cuerpo, son los cuerpos del entorno, es el universo y todo lo que lo compone ${ }^{71}$.

Por su parte, Cabanis, médico y amigo de Destutt de Tracy, sostiene que la idea que el cognoscente posee de los cuerpos supone en él un sentimiento de resistencia u obstáculo. Este, a su vez, se hace posible en la percepción del

69 DestUTT DE TRACY, Eléments d'Idélogie, I, sec. III, cap. IX; Librairie philosophique J. Vrin, París, 1970, pág. 157.

70 DestUTT de TRACY, l. c., pág. 166.

71 DestuTt de TRACY, l. c., págs. 155-156. 
movimiento, vinculada con la voluntad que lo realiza. Así, el sentimiento de un yo diferente de las cosas exteriores surge en la conciencia merced, según Cabanis, al esfuerzo, a un acto de voluntad ${ }^{72}$.

Finalmente, en esta vía abierta por Condillac, encontramos también a Maine de Biran. Éste, parte del sentimiento de esfuerzo como hecho primitivo, a partir del cual surgirán, en común alumbramiento, tanto la libertad, como el mundo exterior material ${ }^{73}$. El realismo volitivo de estos autores, que, sobre la base de la aportación condillaciana, profundiza en su teoría del descubrimiento de lo corpóreo a partir de la sensación de resistencia, será objeto de detenido estudio por nuestra parte en una investigación futura.

Para terminar, quisiéramos referirnos brevemente a un punto que consideramos de extraordinaria relevancia. El procedimiento seguido por Condillac en la demostración de la existencia de lo corpóreo supone la independencia mutua de lo subjetivo y de lo objetivo, de lo interior y de lo exterior, de la conciencia y del mundo. Con la ficción de la estatua se admite, en efecto, la posibilidad de una autoconciencia aislada, exenta de toda referencia a lo objetivo. Condillac piensa que el aislamiento a que los sentidos subjetivos (vista, oĺdo, olfato y gusto) confinan a la estatua, si bien no impide el desarrollo interno de las facultades anímicas y el surgimiento de la autoconciencia, es, en cambio, enteramente inapropiado para la toma de contacto con lo exterior, para proporcionar al cognoscente la conciencia del mundo externo. La primera parte del Traite des sensations pretende afirmar la realidad del sujeto sin la necesaria referencia al objeto, la intimidad de la conciencia, sin la exterioridad de lo otro, el ensimismamiento sin la alteración. Mas, ¿es esto posible? ¿puede afirmarse el yo sin el no-yo?, ¿puede darse una autoconciencia sin conciencia de los objetos?, ¿puede, en fin, nacer la una si no es en un alumbramiento gemelo con la otra? El error de todo idealismo subjetivo, como ya apuntara Kant en la Kritik der reinen Vernunft ${ }^{74}$, radica en el hecho de creer que pueda darse una conciencia subjetiva que no implique la necesaria referencia a la existencia de lo objetivo, de lo exterior. Su tesis es, en efecto, que la conciencia de la propia

72 Cf. Pierre-Jean GeORGE CABANIS, Rapport du physique et du moral de l'homme, Oeuvres, París, 1956, pág. 546.

73 Cf. MAINE DE BIRAN, Essai sur les fondements de la psichologie et sur ses rapports avec l'ztude de la nature, Oeuvres, París, 1932, t. VIII, pág. 177.

74 Cf. I. KANT, Kritik der reinen Vernunft, B 275-279. 
existencia demuestra ella misma la existencia de los objetos en el exterior. No cabe, por tanto, según esto, una conciencia que no sea al mismo tiempo conciencia de lo otro; la clausura del sujeto, la insularidad subjetiva, característica del pensamiento idealista, no dejaría de ser, pues, un artificio metodológico carente de sentido y de consistencia. La autoconciencia hállase, según Kant, ligada de modo inseparable a la conciencia de lo objetivo, como el anverso al reverso de una medalla. De todos modos, la originalidad y fecundidad de la aportación condillaciana no deja lugar a dudas. 